\title{
The Role of Radio in Setting the Agenda for the Electorate and Creating an Atmosphere of Aggression during Elections in the Northern Region of Ghana
}

\author{
By Muhammed Abdulai, ${ }^{*}$ Hadi Ibrahim ${ }^{ \pm} \&$ \\ Mohammed Adams Mashoud
}

\begin{abstract}
This study uses a qualitative approach to examine the role of radio in setting the agenda for the electorate and creating an atmosphere of aggression during elections in the Northern Region of Ghana. Fifteen research participants, made up of seven active listeners and eight reporters, editors, and radio presenters were engaged in conversation analysis and generated data for the study. The study revealed that radio plays a vital role in setting the agenda for the electorate before, during, and after elections in Ghana; this is done by using radio as a channel of communication to send messages of peace. The study also cast light on how radio uses music and entertainment to educate its audiences with messages of tolerance and free, fair and transparent elections. In view of these findings, the study strongly recommends that media practitioners and journalists be trained in media professionalism, focusing on what and how to report during election time in Ghana.
\end{abstract}

Keywords: Media, Elections, Education, Peace, Ghana

\section{Introduction}

Fundamentally, elections are considered to be credible only when the primary principles of democracy are found to inform the processes. Embedded in these principles is the enabling environment that engenders the inalienable right to free discussions and the expression of divergent opinions on issues and public policies deemed to be political by both the political actors and the electorate. This calls for substantial and significant access to an independent, open, and diverse media that exercises civil responsibility by generating balance and impartial information for voters and candidates alike (United Nations Development Programme, UNDP, 2014). The UNDP (2014:1) expressly puts forward the sacred role of the media when it states that "the media has a unique position as both a conveyor and a recipient of information".

In Ghana, the media is regarded as a serious and major stakeholder as well as

\footnotetext{
*Lecturer, Tallinn University, School of Governance, Law and Society, Estonia \& University for Development Studies, Faculty of Communication and Cultural Studies, Department of Communication, Innovation and Technology, Ghana.

${ }^{ \pm}$Commercial Officer, Regional Offices and Foreign Missions, Ministry of Trade and Industry, Sunyani, Ghana.

${ }^{\dagger}$ Lecturer, University for Development Studies, Faculty of Communication and Cultural Studies, Department of Communication, Innovation and Technology, Ghana.
} 
the fourth realm of the state, which is an essential cornerstone of this fledgling democracy. The media draws its fundamental mandate from Ghana's 1992 operating constitution, which seeks to constantly develop an efficient, vibrant, and powerful media that ensures checks and balances on the other arms of government. The expectation is that the media should keep the electorate well informed both in terms of the election process and the policies of those seeking the mandate of the electorate. For instance, while television is the medium most used by politicians in the developed countries, radio is predominantly used in many developing countries (Myers 2008; Zhou et al. 2016; Kioko Ireri et al. 2017).

Generally, the media enjoys certain fundamental freedoms, the exercise of which contributes to the good of society by way of education, balance reportage, and entertainment, among other factors. However, the functions of the media during elections are more of a conundrum in most parts of the African continent, and are seen in how the media acts as a proxy in the battle between rival political groups sowing seeds of discord, divisiveness and hate speech instead of engendering consensus, sober debate and trust among the people (Shiela 2013). The myths surrounding this perceived conundrum remain to be demystified by conscious and well-intended academic endeavor. It must be pointed out that scholars and well-meaning institutions have extensively investigated and explored the relationship between election violence and peaceful elections and development (Mikinda 1996; Matu Ngui 2009; Joey 2012; FOSDA 2015; Adebayo 2016). However, in the case of the relationship between the radio and elections, existing studies tend to focus on other countries in Sub-Saharan Africa and on other areas of Ghana (IMPACS 2004; Owusu 2012; Shiela 2013; UNDP 2014; Yankem 2015).

For instance, through a quantitative study, Yankem (2015) explored the role of radio as a tool for political mobilization in Kenya during the 2013 general elections, with a focus on Nairobi. The study revealed that about $76 \%$ of the electorate who listened to the radio during these elections were exposed to political content through talk shows, news and advertisements. While these research bodies (IMPACTS 2004; Owusu 2012; Shiela 2013; UNDP 2014; Yankem 2015) present an excellent overview of the relationship between the media, elections, election violence, and development in Sub-Saharan Africa, there is paucity of studies on the role of radio in setting the agenda for the electorate and creating an atmosphere of aggression during elections in the Northern Region of Ghana. Therefore, the intriguing question of how radio, as a significant element of the media, plays a role during elections in this part of Ghana persists and begs scrutiny and interrogation. This study therefore, seeks specifically to answer the question: What is the role of radio in setting the agenda for the electorate and creating an atmosphere of aggression during elections in the Northern Region of Ghana?

This study is important because election periods are among the most volatile across the globe, and the use of radio during elections continues in most African countries. The study considers radio as a mass media communication tool because it is the most used medium of communication for political mobilization, ideological and policy propagation in Ghana throughout the election period. In addition, radio is far more affordable and accessible, and broadcasts are often made in local languages that people can understand. The study has chosen the 
election period because in most cases, countries in Sub-Saharan Africa and other developing countries are characterized with violence and an aggressive atmosphere, especially during this period. We define an aggressive election atmosphere as a condition in an election period which has the potential to trigger violence and/or conflict. In the context of Ghana, some municipalities are identified as "hot spots", during elections. In light of this, editors, reporters, and radio presenters make choices about what to report and how to report it, thereby setting the agenda for the electorate and creating an aggressive atmosphere. This study will contribute to the existing literature on media studies because the approach to identifying the specific role of radio during elections in the Northern Region of Ghana is likely to provide rich perspectives and make an important contribution to research on media professionalism in Africa.

The study employs the nominalist paradigm, a qualitative case research design, and conversation analysis with reporters, editors, radio presenters, and active listeners in three municipalities in the Northern Region of Ghana. The paper is structured as follows: review of the literature and theoretical underpinnings, research methodology, discussion, and conclusion.

\section{Conceptualizing the Role of Media in Elections}

According to Odhiambo (2017), the media plays a vital role at the time of elections, and it does that by informing the electorate and playing a watch dog role. Conversely, media and journalists are also seen to be acting contrary to journalistic ethics by indulging in demeanors that tend to fuel election-related violence through their reportage. It is, therefore, imperative to interrogate the role of the media during elections because violence associated with elections have increasingly bedeviled world leaders especially in many parts of Africa. For instance, hate speech and poor reportage chained out by the media resulted in inflamed passions and tensions and led to attacks and reprisal attacks with a radio presenter hauled before the international criminal courts as evidenced in Kenya (Odhiambo 2017; Iriri et al. 2017). It is observed that "elections correspond to periods of heightened media coverage and reporting with each political party wanting to lead the country, these transitional times are brought with competitive language, rising tensions, and occasional political violence, sometimes even resulting in violent conflict" (Caput 2011: 3). This implies that the role of media in furthering the course of elections can make and unmake the electoral process. Therefore, the players and stakeholders in the media fraternity and elections alike have some fundamental and civil responsibilities, the exercise of which is likely to bring good outcomes during election periods.

In addition, several authors in media and elections have noted that election periods are often fragile particularly in Africa (Hoglund 2009; Joey 2012; Adebayo 2016). In light of this, Matu Ngui (2009) recommends that during elections, media players like journalists, and news presenters be trained in media professionalism,

\footnotetext{
${ }^{1}$ Hot spots: In the Ghanaian context, "hot spots" are electoral areas where a little misunderstanding or misinformation could lead to violent behavior by the electorate.
} 
imbued with mind-sets that are conflict preventive, and to eschew reportage that incites divisiveness, antagonism, and has the tendency of resulting in violence that jeopardizes social cohesion and order. Similarly, Caput (2011: 4) noted that in order to achieve efficient and impartial coverage on elections matters, journalists ought to acquire basic skills and knowledge on relevant legal documents and much more be well educated "on the different institutions involved in the organization of elections such as; campaigns rules and regulations, the format of the ballot papers, and the procedures for the announcement of the results".

Furthermore, Windeck (2010) is of the view that the interdependence between the media and the political systems are manifestly apparent. In the interdependence lies an obvious trade off inherent in the systems where information that emanates from the political systems is exchanged for coverage in the media outlets. Thus, the media relies on the political systems for the supply of relevant information, while at the same time, the political systems count on the media systems to have the information efficiently and effectively conveyed to the electorate (Jarren and Donges 2006). Moreover, Joey (2012) noted that the media is located at the second corner of the triangle in political communication with a traditional task of transmitting information from the political actors to the electorate. So, they intermediate between the political players and the messages they generate for the electorate by assisting them comprehend the information as ultimate recipients. Aside the mediating role, the media undertakes independent communication in the form of running political commentary, editorials and/or interviews. This mediation role is often hampered by the forces of incumbent parties as Shiela (2013) observed that the media in new and restored democracy do not always live up to the ideal. They are hobbled by stringent laws, monopolistic ownership, and sometimes, the threat of brute force. Again, intrinsic values are also placed on the postulation that the role of the media in elections are influential and deterministic in nature. By the watchdog role of the media, couple with its powers to provide the platform that informs and keeps the electorate abreast with electoral issues, as well as the influence it wields, the media end up setting the agenda for issues, the candidates' positions and the reasons for voting (UNDP 2014).

\section{The Agenda setting Function of Traditional Media}

This study adopts the agenda setting theory to cast light on the role of radio in setting the agenda for the electorate and creating an atmosphere of aggression during elections in the Northern Region of Ghana. Agenda setting theory is a prominent concept in communication studies that describes the enormous influence of the media in determining the issues the public think about and the extent of salience attached to issues in a nation (Ireri et al. 2017). The theory has a basic tenet that the media may not be successful in determining what we think, but it has an influence on the matters we think about, and how we think about them. It was in this view that Shaw and Martin (1992) observed that the media do not tell us what issues to believe, but suggests issues that people collectively may agree to discuss and probably act on it. The agenda-setting theory was conceptualized by 
Maxwell McCombs and Donald Shaw (1972) to understand the influence of media in shaping people's voting patterns in the 1968 U.S presidential election. However, in the past decades, scholars have applied the concept of agenda setting effects in diverse fields such as communication studies, politics, healthcare, family health, civil rights and business (Zhou et al. 2016). The agenda setting concept is made up of three interconnected aspects -media agenda, public agenda and policy agenda (Shaw and Martin 1992). Media agenda are the issues discussed or covered by media reportage, and public agenda are issues audience members consider salient. The media agenda largely influence matters on the public agenda because they attach prominence to issues on the public agenda (McCombs and Shaw 1972). The three are interrelated, and when an agenda setting process is initiated, they interact and influence each other. Media agenda and public agenda settings are common in the communication research, but policy agenda is usually researched by scholars in the field of political science and sociology (Zhou et al. 2016).

Agenda setting theory operates at three levels: The first level, second level and third level agenda setting (Miller 2005: 270). The first level agenda setting espouses on how people's views about matters are considered salient in a given nation, and determined by the prominence and space of such issues in media coverage (Ireri et al. 2017). Likewise, the second level agenda setting shades light on how media lay emphasis on particular attributes while covering stories, hence directing the focus of audience members towards those features in news reportage in particular tone or affective feelings -negative, positive or neutral of the subject (Zhou et al. 2016; Littau and Stewart 2015). So, by attaching saliences and emphasizing certain characteristics of the issues in their coverage, the media affects what people regards as importance to form an opinion about (Zhou et al. 2016). The third level agenda setting posits that media is not only able to inform what we think about and how we think about issues, but informs us what and how to associate, with salience of interrelationships among issues and attributes that can move between agendas simultaneously ( $\mathrm{Vu}$ Guo and McCombs 2014; McCombs et al. 2014). In this regard, the study is located within the second level agenda setting to explore how the radio lays emphasis on certain issues as salient, and setting the agenda for the electorate and creating an atmosphere of aggression during elections in the Northern Region of Ghana.

As stated earlier, the agenda setting theory was originally conducted to explore the influence of media in shaping people`s voting patterns in the U.S. However, the political factors and media systems in Ghana differ greatly from those in the U.S. As such, some of the assumptions of the agenda setting theory may not operate exactly the same in the context of Ghana (Yeojin et al. 2016). Notwithstanding, the theory is still relevant for this study because the Ghanaian electorate depend on the media messages for information and the media also depends on the environment for information. Therefore, the watchdog role of the media over the society, and couple with its powers to inform and educate the public with electoral issues, the media end up setting agenda for either peaceful or an atmosphere of aggression during election in Ghana. In light of this, the agenda setting effect of the media is capable of shaping the behavior and attitudes of people (Shaw and Martin 1992). Media reportage during election period has great impact on the 
attitudes of the Ghanaian electorate because the media serves as a conduit where most electorate access information. In this vein, the agenda setting concept will provide a strong conceptual foundation to analyze the role of radio in setting the agenda for the electorate and creating an atmosphere of aggression during elections in the Northern Region of Ghana.

\section{Research Design and Method}

This study is located within the nominalist paradigm. The nominalist approach assumes that reality is constructed by individuals in interaction with each other (Bryman 2004; Creswell 2009; Kuada 2012). It further noted that there are multiple and subjective realities. In view of this, reality about the role of radio in setting the agenda for the electorate and creating an atmosphere of aggression during elections in the Northern Region of Ghana could be constructed through the interactions of journalists, radio presenters, reporters and their audiences, and as well as, the interactions of the audiences with the messages disseminated via the radio stations. Similarly, the study adopts a qualitative case study design. The qualitative case study design is focused on an explanatory, exploratory and descriptive interrogation of the phenomenon (Yin 2003). As a result, the study has employed an explanatory and descriptive investigation into the role of radio in setting the agenda for the electorate and creating an atmosphere of aggression during elections in the Northern Region of Ghana. The case study approach was adopted because it offers the researchers the opportunity to engage with the participants within their real-life context, and restricted the researchers from having any control over the events in the setting of the participants (Yin 2003). The purposive sampling techniques was used for the study. This sampling technique allows for the deliberate selection of respondents whose responses are likely to generate useful data for the study (Leedy and Ormrod 2005). In all, fifteen media practitioners, reporters, editors, and active listeners to the radio stations selected were engaged in conversation analysis. The number of study subjects who were represented in the study are illustrated in the table 1 .

\section{Research Setting and Data Sources}

Ghana has 16 administrative regions, five of which are located in the Northern Savannah Ecological Zone. These five regions are: Upper West, Upper East, Northern, North East and Savanna regions (Ghana Statistical Service 2010). The study was carried out in the Northern Region. The study adopts conversational analysis technique as a tool for data generation. Bryman (2004: 365) defines conversation analysis as the "analysis of talks/conversations as it occurs in natural situations". 
Table 1. Respondents Profile

\begin{tabular}{|l|c|c|c|}
\hline $\begin{array}{l}\text { Codes of } \\
\text { Study subjects }\end{array}$ & $\begin{array}{c}\text { Radio Stations of the study } \\
\text { subjects/Listeners }\end{array}$ & Sex & Responsibility \\
\hline 1.ZR & Zaa Radio-99.3 & $\mathrm{M}$ & Editor \\
\hline 2. RS & Radio Savannah-91.2 & $\mathrm{F}$ & Reporter \\
\hline 3. MT & Might FM-90.5 & $\mathrm{F}$ & Radio presenter \\
\hline 4. EG & Eagle FM-94.1 & $\mathrm{M}$ & Radio presenter \\
\hline 5. GM & Gmantambo Radio-96.1 & $\mathrm{M}$ & Radio presenter \\
\hline 6.NS & Northstar Radio-92.2 & $\mathrm{M}$ & Reporter \\
\hline 7.BR & Bishara Radio-97.7 & $\mathrm{M}$ & Editor \\
\hline 8.KS & Kesmi FM 107.1 & $\mathrm{F}$ & Radio presenter \\
\hline 9.LL & Active listener & $\mathrm{M}$ & Active listener \\
\hline 10.LP & Active listener & $\mathrm{F}$ & Active listener \\
\hline 11.LC & Active listener & $\mathrm{F}$ & Active listener \\
\hline 12.LY & Active listener & $\mathrm{M}$ & Active listener \\
\hline 13.LU & Active listener & $\mathrm{M}$ & Active listener \\
\hline 14.LW & Active listener & $\mathrm{M}$ & Active listener \\
\hline 15.LM & Active listener & $\mathrm{F}$ & Active listener \\
\hline
\end{tabular}

In other words, conversation analysis is considered as a form of data collection technique that involves conducting conversations with small respondents to explore their perspectives on a particular idea, program, subject or situation (Creswell 2009). At the start of the study, all the stakeholders were identified and fifteen editors, reporters, radio presenters, and active listeners were selected and used for detailed and comprehensive data collection. The active listeners and other participants were selected to solicit their views on the agenda setting function of radio, during elections in the Northern Region of Ghana.

We selected the study participants who were willing to provide information by virtue of their knowledge and experience on the role of radio in setting the agenda for the electorate and creating an atmosphere of aggression during elections, and excluded those who had inadequate knowledge and experience on the role of radio in setting the agenda for the electorate and creating an atmosphere of aggression during elections. After the identification and selection of the participants, we had long conversations with all the participants. Each talk/ conversation lasted for about 1 hour and 30 minutes, and the conversations were conducted face-to-face with each participant on different days in the month of October 2018. Some of the questions posed to the study participants are outlined as follows: describe to me how the radio is used to ensure peaceful election in Ghana. Tell me how we can prevent the use of indecent languages on the radio during and after elections. Do you have code of ethics on how and what to report during election time in Ghana? How are these codes of ethics enforced? All the conversations were audiotaped and transcribed afterwards. This technique of data collection was used because we wanted detailed information about how radio is used in setting the agenda for the electorate and creating an atmosphere of aggression during elections in the Northern Region of Ghana. 
In terms of data analysis, the thematic analysis technique was used to analyze and identify the main themes in the study. Thereafter, the open coding system was applied and coded the data, and identified the common strand of themes. Again, the axial coding was used to establish relationship between themes (Saldaña 2013). After coding the data, we grouped them into themes according to their similarities. Classical content analysis was used aftere the themes were generated with their respective sub-themes. Classical content analysis is similar to constant comparison analysis (Abdulai et al. 2017). The number of times each descriptive code occurred was ranked and the most important concepts were identified as the themes. In connection with data interpretation, the hermeneutic approach was used. The meaning interpretation perspective focused on conducting a very close detailed reading of texts. This is done to acquire a profound deep understanding of the texts to discover deeper meanings that are embedded within the texts (Neuman 2014).In a similar vein, we conducted a detailed readings of the entire data and discovered the deeper meanings explicitly found in the research subjects responses.

In order to ensure the trustworthiness of the findings, the member crosschecking approach was applied where the transcribed data was presented back to four of the radio presenters and reporters, and they assessed the extent to which the data represented their perspectives as recorded. Again, informed consent preceded participation, and the application of inclusion and exclusion criteria for participant selection (Marshall 2003).

\section{Findings and Discussion}

This part of the study is a presentation of the research findings, and discussion on the role of radio in setting the agenda for the electorate and creating an atmosphere of aggression during elections in the Northern Region of Ghana. Two themes have been discussed: radio, agenda setting and atmosphere of aggression during elections, and the role of radio in electoral education.

\section{Radio, Agenda setting and Atmosphere of Aggression during Elections}

Given that the society depends on the media for information during elections to make informed decisions, and given that the media sets the agenda for the electorate on issues they consider salient during elections make it expedient to shed light on how the media is used to set agenda for hate and aggression in a developing country context. In view of the dependency relationship between the media and the society, one of the research participants, a radio presenter was asked to explain how the radio sets its agenda during elections in Ghana. In response, the participant expressed:

"The radio serves as a channel through which elite's set their agenda,... eeh... they see the media as a powerful resource and use it to influence electorate, mobilize electorate, and to win and consolidate political power" (4-EG). 
From the words of the research participant, it implies that the radio is a powerful tool which can be used to capture the attention of the electorate by elites in society, mobilize the electorate, capture and maintained political power. In addition, the expression provides a more nuanced understanding of agenda-setting effects on the end users of traditional mass communication channels (Zhou et al. 2016), and further enriches our understanding of Lippmann's (1922) metaphor that the news media construct a pseudo-environment for the mediated end users. This implies that the radio and other traditional mass communication channels which most end users trust as "authentic messengers" in most cases creates false content for the mediated end users because the environment where the media practitioners access their information is too complex for direct experience (Lippman 1922). Besides, most end users do not critically check the content produced via radio and other traditional mass communication channels. Relating the theoretical basis to the submission of the participant, it means that the information the Ghanaian electorate' access via the radio and other mass communication channels before and during elections are too complex, and are often generated by people with selfseeking interests.

In connection with the same issue, one of the research participants, a news reporter asserts:

"we are public radio station, so, our agenda is set by the national policy. For instance, if we want to have a credible election, our policy should be aimed towards ensuring peaceful eerh...elections through dissemination of messages of peace and peace education (2-RS).

The views expressed by the research participant resonate with the mutual relationship between the media, public and policy agenda setting perspectives. In this regard, the media agenda is the set of issues addressed by media sources, and the public agenda are issues the public considers as salient (Shaw and Martin 1992). Therefore, both Ghanaian public and private radio stations could influence the public agenda before, during and after elections. On one hand, media personnel can decide to act responsibly by disseminating information that is unbiased and devoid of unnecessary hype that is designed to promote peace during elections. On the other hand, media practitioners can also decide to disseminate false or unsubstantiated information during elections to create an atmosphere of aggression and violence. The revelation above is in line with the findings of Iriri et al. (2017) that current reportage by media personnel in Africa during elections is mainly motivated by factors such as ownership, geopolitical location and religious/ethnic inclination. As a result, the immense influence of the media requires that media personnel are professionally trained to report social-political issues in a conflictsensitive and responsible manner before, during and after elections in Ghana.

Moreover, as part of the media role in elections, it creates a platform for politicians to sell out their policies to the electorate in order to canvass for votes. It also allows citizens to criticise the policies of various political parties in order to promote participatory democracy. In line with this thinking, one active listener of radio indicates: 
"Journalists are free enough to publish what they think is right, ee... nobody is being arrested to say because he or she has published a material that is not palatable in the interest of the state, what the government can do is to file a suit of libel against the person and when a radio station is guilty, they found culpable of what they have done" (15- LM).

It can be inferred from the excerpt of the participant that the freedom given to the media in Ghana has made it possible for media personnel to publish whatever information they feel is relevant for the end users. In view of this, audience and for that matter politicians depend on the media to express themselves to gain satisfaction and also win and consolidate power. This dependency relation between the media and the audience is in keeping with the media system dependency theory (Ball-Rokeach and DeFleur 1976) which posits that there is an internal link between the media, the audience, and the social systems. In the context of Ghana, politicians create dependence relationship with their target audience to achieve their political ambitions by using the power of the media to disseminate their policies and programs to influence electorates to either win power or consolidate power. However, the freedom given to the media and journalists have often been misused in most African countries including Ghana. In some cases, the media is used to create an atmosphere of aggression and violence during elections. For instance, Adebayo (2016) revealed that the role the media played as a propaganda weapon during the Rwandan genocide, suggests that the media and its effect on society cannot and should not be underestimated. Relating this scenario to the 2007-8 post-election violence that rocked Kenya, Hoglund (2009) observed that radio broadcasts shortly after the election contributed to fuelling the postelection violence. The study further noted that the major culprits were the vernacular radio stations that broadcast in the local languages of Luo, Kikuyu, and Kalenjin, among others.

Again, the media as a major stakeholder and the fourth arm of government has played a tremendous role in strengthening our democracy and electoral processes in Ghana. It does this through checking the other arms of government (executive, legislature and judiciary), and also uses its powers to allow politicians and citizens to express themselves on media platforms in order to exercise their freedom of speech, and contribute to national development. In view of this, in one of our conversations, a question was posed to the participants to describe the role of the radio during elections and one of the participants explained:

"In an electoral process radio has the capacity to calm the source of information, the source of education, the source of instructions on how the electoral process is due" (13-LU).

In the opinion of the participant, it implies that the media has the capacity to inform and educate people about the dos and don'ts of elections and also instruct the electorate on how to conduct themselves at polling stations. This is also in line with a study in Kenya where it was revealed that in open democracies, citizens not only acquire vital information about various topics from the mass media, but they 
also learn how much importance to attach to the issues in news (Iriri et al. 2017). In another development, when a question was asked in connection with media freedom and elections, another active listener narrated:

"I feel that we still remain in the military regime, ee... we have given people ee... the freedom to speak their minds, so that they can participate fully and actively in the discourse of national development, but seriously, boss, some people are misusing it" (9-LL).

The submission above suggests that the liberty given to Ghanaians to freely express their opinions without fear or favor are often been misused by creating an atmosphere of aggression and violence. This assertion supports the findings of the reports of the Media Foundation for West Africa language monitory on radio (2013) which highlighted that the use of indecent languages on radio went up from $14 \%$ to $16 \%$ as compared to the preceding two weeks after the 2012 election verdict in Ghana. In this context, the freedom given to radio stations and other media outlets in Ghana, can either promote peace, or create an atmosphere of aggression and violence depending on the decency of language used by the radio stations and the form of information disseminated to the general public. Similarly, a question was asked in relation to how media ownership could have an effect on creating an atmosphere of aggression during elections in Ghana, in response, one of the participants, 7-BR had this to say:

"One of the challenges is that a lot of politicians in Ghana have radio stations that are actually causing problems for the country during elections. When politicians own radio stations, the risks are that, they can use it in their favour during election, Eee...they can use it to misinform, send out wrong information, and use it to create tension in the city, towns and villages. So, there is always a threat of misinformation".

Extracts from the data has not only cast light on how media ownership by few wealthy politicians are used to advance their self-seeking political interests, but are also used as sites for political misrepresentations and misinformation. The expressions also resonate with the propaganda model as articulated by Chomsky and Herman (1988) where they explained that ideally mass media are meant to report events objectively, allow the people to make informed political choices and check on the government power through investigative journalism. However, this is not the case in many instances in Ghana. The revelation highlighted that most Ghanaian influential politicians' own media outlets and news reportage from these media outlets favor the interests of the owners of the media outlets. This way could create an atmosphere of aggression during elections, and may subsequently cause violence elections. In addition, the ability of affluent politicians to own and control some media outlets in Ghana can be interpreted from what Lippmann`s describes as the world outside and the pictures in our heads (Lippmann 1922: 49). In the context of Ghana, the world that we will have to deal with is out of reach, out of sight and out of mind because it has to be explored, 
reported and imagined by others, in this case, the few affluent Ghanaian political elites, and the media owners. So, "the pictures inside the heads of the others" that are acted upon by the Ghanaian electorate could be meant to satisfy the interests of the few Ghanaian political elites, the media owners and the affluent in the society. Concerning the same issue, another research participant, 2-RS expressed:

"... ownership is a problem in the radio industry. Politicians have decided to own their own radio stations and by so doing they use the stations to propagate their own ideas and policies. Eee.. their main concern is not about the welfare of the public, but their own self-seeking political interests".

The above information has also shed light on the effects of media ownership by politicians on balance and accurate reportage. In this regard, owners of media houses have the power to influence the production and reproduction of media content to satisfy their egoistic interests. This argument resonates with Sheila (2013) postulation that the media are sometimes used as proxies in the battle between rival political groups, in the process sowing divisiveness rather than consensus, hate speech instead of sober debate, and suspicion rather than social trust.

\section{The Role of Radio in Electoral Education}

As an element of mass media, radio has been extensively used for education, entertainment, social development and information sharing in both developed and developing countries. During our discussion on how the radio is used in setting the agenda for the electorate, and creating an atmosphere of aggression during elections period in the Northern Region of Ghana, the participants were asked to describe the role of radio in educating the electorate during elections and these were the views expressed by a radio presenter:

"The radio educates us about the process of voting, free, fair and transparent elections, violence free elections. Eer... as such that, it also educates us about the policies and ideologies of the various political parties" (14-LW).

In the aforementioned quotes, the participant has illuminated how radio serves as a major source through which the public receives education on the policies, programs and ideologies of the various political parties in Ghana, and as well as an avenue for peace education during elections. In support of this view, Adebayo (2016) explained that the media wields enormous influence regarding how the public view and interpret electoral violence, and provides interpretative frameworks that can lead the public to conclude that either the election was free and fair or was not free and fair. In connection with the same matter, another research participant, a news editor narrated:

"When you look at the last election, we were able to use opinion leaders, we were able to use religious figures, and we were able to use international 
figures, role models to send out messages of tolerance. ... and also, like I said before, radio sends out messages and music and drama which will all persuade us, so radio is so important before elections. Is so important during elections because it is the medium through which you send messages instantly" (1-ZR).

Generally, the participant revealed that radio plays a vital role in elections by using people in authority to advocate for peace before, during elections. In addition, as a mass media communication tool, the radio is the most used medium of communication during elections in Ghana because it reaches out to the general public instantly. The statement also suggests that radio as part of its mandate uses music, and drama in the form of entertainment to persuade the audience with messages of peace and tolerance during elections. Furthermore, the quality of the content produced by media companies are inextricably linked to the quality of human resource and equipment they possess. In relation to this, a question was posed to ascertain some of the challenges faced by media houses in the Northern Region of Ghana, and one of the participants revealed:

"Well, for example, during the last election what we saw was that, the quality of human resources of our radio stations were not the best. Because radio stations do not pay well, their staffs are not the best that we can have. And the quality of interviewing was poor, there was no investigative journalism, nonviolence dissemination of information, eeh... it was clear that they were not doing their work" (4-LY).

The qualities of human resource used in the media houses are very crucial for the creation and re-creation of quality media content for the general public. However, the statement made by the participant indicates that most media houses in the region do not have enough professionally trained personnel to offer quality reportage. Relating this finding to the work of Lynch and McGoldrick (2005) which highlighted that in many parts of Africa, few journalists and media personnel are well trained in the area of peace journalism and conflict analysis. In this regard, the inability of some journalists and media personnel to conduct their work professionally and conflict sensitive reportage could have direct effects on the electoral processes during election because those who are supposed to educate and inform the general public are not well trained, informed, and equipped with professionalism. The data also indicates that some media houses do not pay their staff well and this could lead to unprofessional conducts such as resorting to taking bribes to supplement their meager salaries. In a similar vein, the quality of media personal used, and the quality of training given to media personnel could have an effect on the outcome of the reportage during elections.

Our analysis of the data revealed that the radio is a societal teacher and has the ability to shape the opinion and attitudes of listeners especial during elections. To this end, in response to a question on the influence of the radio during elections, one of the study participants noted that: 
Vol. 6, No. 4 Abdulai: The Role of Radio in Setting the Agenda for the Electorate and...

"In an electoral process, radio has the capacity to calm down the source of information, the source of education, the source of instructions on how the electoral process is due" (3-MT).

From the statement of the participant, it is very clear that radio is used to educate Ghanaian citizens during elections. They do this by giving out guidelines about the processes involved in pre-election activities such as registration of new voters, exhibition exercises. For example, the steps involve in casting votes, voting ethics, conducts at the polling station among other factors. It can further be interpreted to mean that radio has the capacity to give instructions on the dos and don'ts of electoral processes. This understanding is in keeping with the findings of Foster (2010) that the media is used to mold decisions of the electorate and to enlighten people on happenings in the social sphere.

\section{Conclusion}

The paper discusses the role of radio in setting the agenda for the electorate and creating an atmosphere of aggression during elections in the Northern Region of Ghana. Throughout the discussion, the fifteen research participants highlighted that radio plays a vital role in national elections by using people in authority to advocate for peace before, during and after elections. Further, the study revealed that radio as part of its mandate educate its audience with messages of peace and tolerance in order to ensure violence-free national elections. The study illuminates how some media houses and journalists have abused the media as the fourth estate/fourth power by using it to create an atmosphere of aggression during elections. In view of these findings, the study strongly recommends that media practitioners and journalists be trained in media professionalism, focusing on what and how to report during election time in Ghana. Finally, interpretations of the empirical data also cast light on how the media can either promote peaceful elections or create an atmosphere of aggression or violence based on the decency of the language used by radio presenters, reporters, journalists and political activists. Therefore, the study suggests that radio presenters, reporters, and political activists should be educated well on the decency of language used in the media to improve the quality and standards of radio presentation in Ghana.

The findings of this study should be carefully interpreted because the study focuses on the role of radio in setting the agenda for the electorate and creating an atmosphere of aggression during elections in the Northern Region of Ghana. Therefore, generalizing the findings beyond the Northern Region of Ghana may not be scholarly. Again, due to the limited time and resources used for the study, not all the components of media and elections were covered. In connection with this, future studies should consider looking at the role of the media in promoting democratic culture in Ghana. 


\section{References}

Abdulai, M., Ibrahim, H., Mohammed, A. (2017). Communicating Across Cultures in Multinational Ibis West Africa. International Journal of Intercultural Relations, (58): $42-53$

Ball-Rokeach, S. J., DeFleur, M. L. (1976). A dependency Model of Mass-Media Effects". Communication Research 3 (1): 3-21.

Bryman, A. (2004). Social Science Research Methods. New York: Oxford Press

Caput, A. (2011). Preparing Media Coverage of Elections: A Training Guide. Radio for Peace Building in Africa. Retrived: https://www.sfcg.org/programmes/rfpa/pdf/2011 Responsible_Media_Elections_Color_EN.pdf

Chomsky, N., Herman, E. (1988). Manufacturing Consent: The Political Economy of Mass Media. New York: Panthesis.

Creswell, J. W. (2009). Research Design: Qualitative, Quantitative and Mixed Methods Approach (3rd edition). UK: Sage Publications.

FOSDA (2016). Peace Animators. FOSDA Luads SEND-Ghana's Peace Anmators Initiative. Retrieved October 20, 2016, from www.citionlinenews.com.

Foster, S. (2010). Political communication. Edinburgh: Edinburgh University Press.

Gallois, C., Shuang, L., Zala, V. (2011). Introduction to Intercultural: Communication, Global Cultures and Context. London. Sage Publications.

Ghana Statistical Service (2010). Population and Housing Census. Retrieved from http:// www.statsghana.gov.gh/docfiles/2010phc/2010_POPULATION_AND_HOUSI NG _CENSUS_FINAL_RESULTS.pdf

Hoglund, K. (2009). Electoral violence in conflict-ridden societies: concepts, causes, and consequences, Terrorism and Political Violence, 21.

IMPACS (2004). Howard, Ross, 1946: National Library of Canada Cataloguing in Publication. An Election Reporting Handbook

Jarren, O., Donges, P. (2006). Politische Kummunikation in der Mediengesell-schaft, (2nd Edition).

Joey, E. (2012). Ensuring Peaceful Elections in Ghana and Africa. Africa reality. Retrieved October 20, 2016.

Adebayo, J. O. (2016). Fostering nonviolent elections in Africa through conflict-sensitive reportage of elections, African Security Review, 25:3, 303-315.

Ireri K., Ongus, E., Laboso, E., Kangai M., Jared O. (2017). First Level Agenda-Setting: A Study of Press vs. Public Opinion in Kenya. African Journalism Studies, 38:3-4, $26-49$.

Kuada, J. (2012). Research Methodology. A project Guide for University Students: Aalborg University, Samfunds Litteratur.

Leedy, P. D., Ormrod, J. E. (2005). Practical Research: Planning and Design. $\left(8^{\text {th }}\right.$ ed.). New Jersey: Pearson/Prentice Hall.

Lynch, J., McGoldrick, A. (2005). Peace journalism. Stroud: Hawthorn Press, 2005.

Makinda, S. (1996). Democracy and Multiparty in Africa. The Journal of Modern African Studies, 552-573.

Marshall, P.A. (2003). Human Subjects Protections, Institutional Review Boards, and Cultural Anthropological Research. Anthropology Quarterly, 76(2): 269-85.

Matu, N. (2009). Community Radio and the Post-Election Violence in Kenya. AMARCAfrica.

McCombs, M. (2004). Setting the Agenda: The Mass Media and Public Opinion (Cambridge, MA: Polity Press.

McCombs, M.E., Shaw, D. (1972). The Agenda-Setting Function of Mass Media. POQ, (36); 176-187 
Vol. 6, No. $4 \quad$ Abdulai: The Role of Radio in Setting the Agenda for the Electorate and...

Miller, K. (2005). Communication, Perspectives, Processes and Context. Second Edition. Mc Grew Hill.

Myers, M. (2008). Radio and Development in Africa. A Concept Paper Prepared for the International Development Research Centre (IDRC) of Canada.

Neuman, W.L. (2014). Social Research Methods: Qualitative and Quantitative Approaches $\left(7^{\text {th }} \mathrm{Ed}\right)$. Person Education Limited.

Odhiambo, S.A. (2017). The Media and Election-related Violence in Africa: Lessons from Kenya. Southern Voices Network for Peacebuilding Africa. Program Policy Brief. No. 11

Owusu, W. Y. (2012). The Ghanaian Media Landscape. University of Oxford Press.

Saldaña, J. (2013). The coding manual for qualitative researchers. Sage Publications.

Shaw, L.D and Martin, E. S. 1992.The Function of Mass Media Agenda Setting. Journalism \& Mass Communication Quarterly. 69: 902.

Zhou, S., Kim, Y., Yunjuan L., Fei Q. (2016). Is the agenda set? State of agenda-setting research in China and Korea, Asian Journal of Communication, 26:6, 566-582.

UNDP (2014). Media and Elections. "A guide to Electoral Practitioner" file:///C:/Users/ MUHAMMED/Downloads/2038C-UNDP-Media_and_Elections_LR.pdf.

Vu, H. T., Lei, G., McCombs, M.E. (2014). Exploring "the World Outside and the Pictures in Our Heads": A Network Agenda-Setting Study. Journalism \& Mass Communication Quarterly, Vol. 91(4) 669-686. Sage.

Lippmann, W. (1922). Public Opinion. NY: Macmillan.

Windeck, F. (2010). Political Communication in Sub-Saharan Africa and the role of New Media. The Konrad-Adenauer-Stiffung International Reports. Issue 10.

Yankem (2015). Radio as a tool of political mobilization in Kenya during the 2013 general elections: a case study of Nairobi country. Unpublished master's thesis.

Yin, R. K. (2003). Case Study Research: Design and Methods. (3rd Ed) California: Sage Publication. 